\title{
Communication Source Preference and Utilization of Development Information in Rural Communities of South-South, Nigeria
}

\author{
Itari, Paul Edet (Ph.D.) $)^{1}$, Costly M. Erim (Ph.D. $)^{2}$ \\ ${ }^{1}$ Department of Continuing Education and Development Studies University of Calabar, Calabar - Nigeria. \\ ${ }^{2}$ Department of Continuing Education and Development Studies University of Calabar, Calabar - Nigeria.
}

\begin{abstract}
This study investigated the extent to which communication source preference relates to utilization of development information in rural communities of South-South, Nigeria. The study adopted the descriptive survey design. The population comprises of all the adult males and females in this area. A sample size of two thousand and twenty-six respondents (rural dwellers) was selected through multi-stage sampling technique for the study. Questionnaire was used for data collection. The instrument which was validated by two experts in relevant fields has two parts: part A elicited the respondents' bio-data, while part B consisted of five items to elicit information to answer the research hypotheses. The items were structured on a four-point scale. In the study area, the instrument was administered personally by the researchers and with the help of research assistants to the respondents. Percentages were used to analyse the bio-data information provided while Anova and multiple regression analysis were employed as statistical tools to address the items in section $B$ of the questionnaire. The results show that Communication Source Preference had significant joint effect on utilization of development information among rural dwellers $(F=52.917 ; p<0.05)$. The relative effect of the predictors shows that interpretational sources - town criers, community leaders, visit/contacts, extension agents, etc. $(\beta=.162 ; p<0.05)$, radio $(\beta=.156 ; p<0.05)$, television $(\beta=.152 ; p<0.05)$, Newspaper/Magazines $(\beta=.086$; $p<0.05)$ and Libraries/information centres $(\beta=.065 ; \quad p<0.05)$ had significant effect on utilization of development information. It was recommended that like county paths, communication channels need to be kept open, frequented and sometimes repaired if they are to continue to be recognised as viable sources of information for development. Above all, such channels must be made informal, democratic and horizontal to elicit the participation and choice of the rural people in development experiment.
\end{abstract}

Keywords: Communication, Source preference, Development information, South-South.

\section{Introduction}

Development communication is simply defined as the use of communication to promote social development. It refers to the practice of systematically applying the processes, strategies, and principles of communication to bring out positive social change (Quebral, 2001). It is essentially an activity involving the dissemination of information. However, for any information to be utilized by the people, they must not only first of all know about it, but the information may come from different sources. The source of information available to the local people include among others interpersonal sources (such as visits/contacts, town crier/community leaders, extension agent, relatives, fellow citizens etc.), and non -interpersonal sources (such as television, radio, magazines, films, cinemas, posters/leaflets, and libraries/other information centres).

Over the years, a number of scholars have reported the role of communication source in stimulating changes in the people's behaviour. Ganpat and Seepersad (1996) observed that the constant interaction with an information source influences utilization. It has been established that a variety of information sources are necessary in the dissemination of information (Voh, 1979; Obibukaku \& Hursh, 1984). Williams (1984) in his study of sources of information on improved farming practices in some selected areas of the then Western region stated that farmers sought information on improved farm practices from many sources. Rogers et al (1995) reported that, utilisation of improved farm practices is a function of communication.

Information source has been known to influence persuasive efficiency and eventual use/utilisation of an innovation. Though information dissemination is a major constraint to research efficiency and innovation transfer, a source which the audience holds in high esteem appears to facilitate persuasive efficiency and vice versa. People, especially the rural dwellers have been shown to respond particularly well to specific sources because they hold and consider such sources in high esteem, highly credible, expert, trustworthy and close to the people (Solomon et al, 2001; Emenyeonu, 1987; Lazarfel \& Bereson, 1965). In a study to determine the relationship between communication and utilisation of agricultural innovation, Emenyeonu (1987) indicated that both the educated and uneducated respondents relied heavily on the extension agent as a dominant source of information. Ononamadu (1984) also showed that farmers in the Awka and Nsukka agricultural zones of 
Anambra state learnt of recommended new inputs from extension agents. In another study, Uzuegbunam (1981) found that $81 \%$ of his subjects became aware of the National Accelerated Food Production Project (NAFPP) and its innovation packages from extension workers. In all these studies, the extension agent was not only an important source of information but there was a significant association between farmers' utilisation index and their frequency of contact with the extension staff. The major reasons given for the overwhelming reliance on the extension agent as a favourable source are that he was accessible, credible, close to the people, respected and above all, trustworthy. Therefore, effective communication in rural areas still attaches more importance to the source rather than the content of information received.

Herzog et al (1968), still working on the question of source credibility in Brazil, found out that in an array of information sources, the extension agent was ranked as the number one source of information by 1,307 farmers used in Minas Gerias. Neighbours/friends came second while the radio was ranked third. In addition, they found that only about $25 \%$ of the farmers preferred agricultural broadcast to music and entertainment. Nonetheless, $64 \%$ said that their source of agricultural preference was still the radio. When questioned on the degree to which the radio has influenced their choice and adoption, 25 agreed that the radio has actually influenced them. This is understandable because they were asked to rate radio against other important sources of agricultural information - extension agents, neighbours/friends and newspapers (Ojebode, 2002).

MacLeod's (1971) survey which was earlier reported, sought to find out the level of credibility credited to some media of mass communication. She found out that next to television, $69.2 \%$ of the respondents found the radio very reliable and very credible. The cinema ranked lowest among the six media studied.

Specific information sources have been found to be important at specific stages of innovation diffusion. The Bureau of Agricultural Economics reported that mass media, such as the radio, are important information sources at awareness stage of adoption process. On the other hand, personal sources, such as visits, contacts, friends, demonstrations, etc. have been reported to be especially important at the trial and adoption stages. Williams (1984) maintain that the mass media are highly valuable not only in making farmers aware of improved agricultural practices but also in adoption stage of adoption process.

Also, in a study, Soola (1999) found that indeed, mass media, particularly the radio, are popular with the rural people. The study noted that the subjects in the sample are well exposed to mass media messages, and affirms that mass media are the most potent channels for generating awareness about family planning, but do no exert sufficient influence on adoption of innovation or improved practices. However, interpersonal communication was seen to be potent between spouses, among friends, neighbours and relatives. Various interpersonal sources, he established, have been confirmed to be influential in adoption, especially at the final stage of decision-making.

Adams (1982) noted that the information channels used by farmers are mass media including radio, television and especially newspapers, contact with extension agents and with other farmers. Williams (1984) in his study of sources of farm information indicated that agricultural extension agents were the most important source closely followed by radio, and then, contacts between fellow farmers. Obiuaku et al (1984) in their diffusion studies in Eastern Nigeria found that radio or regular access to it was a major means of reaching the farmers. Grimmelt (1985) also supported this view when he found that, radio was well utilized in Nigeria by farmers. His study also indicated that over $60 \%$ of all farmers in Nigeria had radio sets and that many farmers listened to agricultural programmes on a daily basis. According to the study, local radio appeared to have greater credibility to farming audience to other sources. In his contribution to sources of getting farm information, Okafor (1981) indicated that information could be disseminated through news releases, radio messages and television programmes.

The use of information from a particular source may be determined by the source credibility as indicated in some of the findings above. It may also be determined by the amount of confidence a particular source enjoys from the users of the information or how reliable that source is.

The power of prestige source to assist persuasive communication among the people is further demonstrated in the peculiar sales ability of some of the stars in the media galaxy. For instance, the use of an Okocha, Sunny-Nneji, Omotola-Kehinde or any of the stars in the sports, music or movie industry will make the audience regard the stars as credible source of information. In the rural communities, the use of people who fit the preconceived idea of wisdom in that culture (e.g. traditional leaders, elders, educated men, etc.), make them seen as credible sources of information (Mchombu, 1992; Ifidon \& Ahiauzu, 2005).

Highly specialized sources, directed to special interest, occupation or social groups have been observed to be very important for their particular audiences. The audience for such specialized communication apparently regards the information as voicing their concerns and interests, and they are thus, more likely to accept its advice. Lazarfel and Bareson (1965) supporting this observation, reported a study conducted to find how doctors came to utilise a new drug. It found out some indications that learned journals devoted to special branches of medicine were more influential among specialist practitioners than were the journals directed to the profession as a whole. The effectiveness of such communication, the scholars observed, was increased by the fact that 
exposure to the information on the journals was highly selective in accordance with the group's norms and interests. This trend is similar to agricultural communication or any type of communication directed at the rural people who have special interest and occupation as it were.

Apart from source determining the choice of the preference or any choice of a medium, there are the other factors, which the rural dwellers take into consideration when making a choice of a medium or media. Also, Lazarfel and Berelson (1965) are of the opinion that, another reason why people may prefer or utilise an innovation conveyed by a particular medium is simply because, they believe the media opinion to be in accord with the majority view. For instance, many rural dwellers may vote for a candidate during election just because their community leader, priest, or any of the other influential persons say they should. Sometimes, this is done because of the opinion of other average citizens. In cases like this, individuals' choice of a medium is not because of a source prestige, its credibility, acceptance or confidence it enjoys, but because they want to stay with the crowd.

Again, Lazarfel and Berelson believe that people prefer one medium to another not solely because the source is highly revered one but also because of the user's status and literacy level, affordability and availability of the channel and, the spread of the message carried by the medium.

\subsection{The problem}

Reports of earlier research on the use of media information for development, especially rural development have dwelt on channels, amount, type and quality of communication necessary to support development initiatives and objectives. Some of this study has also emphasized the impact of media use as provided in rural development packages and programmes, indicating the level of effectiveness or otherwise of these media. However, there is limited information and research on source preference that may relate to or influence the utilization of development information. If governments' many initiatives, interventions and efforts aimed at rural development are to have any effect at all, then the sources of information available to the rural people and their preferences must be investigated. It is for this particular reason that this research was undertaken.

\subsection{Purpose}

The purpose of this study therefore was to find out the source preference practices as it relates to information utilization in the rural communities of south-south, Nigeria.

\subsection{Significance}

The findings of this study will be beneficial to the primary audience (the local people). This is so because the work is designed to be part of a consciousness raising and consciousness changing process ongoing in rural process development packaging. Secondly, the work is intended to influence the political process, assist government and others concerned with development planning and ensure that the practice of both community and rural development is never again done without information being part of it so as to ensure that development is people and not government driven.

\subsection{Research questions}

The research questions are;

1. What is the distribution of respondents who utilize development information by age?

2. What is the distribution of respondents who utilize development information by marital status?

3. What is the distribution of respondents who utilize development information by educational status?

4. What is the distribution of respondents who utilize development information by occupation?

5. What is the distribution of respondents who utilize development information by sex?

6. To what extent does source preference relate to the utilization of development information?

\section{Methods}

The study which adopted the descriptive survey design, aimed at investigating the extent to which communication source preference relates to the utilization of development information in south-south geopolitical zone of Nigeria. From this zone, two thousand and twenty-six adult male and female respondents were selected from three out of the six states in the zone as samples for the study.

\subsection{Instrument for data collection}

Data was collected using the questionnaire which was validated by experts in Guidance and Counselling from Educational Foundations department, University of Calabar, Calabar. The questionnaire which was administered personally by the researchers and with the help of research assistants to the respondents andretrieved immediately was structured on a modified four pointLikert scale of Strongly Agree (4), Agree (3), 
Disagree (2), Strongly Disagree (1). Percentages were used to answer research questions 1-5, while Anova and multiple regression Analysis were used for research question 6.

\subsection{Method of data analysis}

Descriptive statistics of frequency counts and percentages were used to answer research questions 1-5, while Anova and multiple regression were used to answer research question 6.

\section{Results}

The results of the study were presented on tables 1-7 below

Research Question 1: What is the distribution of respondents who utilize development information by age?

Table 1: Distribution of respondents (rural Dwellers) by age.

\begin{tabular}{|c|c|l|}
\hline AGE & FREQUENCY & PERCENTAGE \\
\hline $16-25$ & 128 & 6.3 \\
$26-35$ & 194 & 9.6 \\
$36-45$ & 448 & 22.1 \\
$46-55$ & 560 & 27.6 \\
$56-65$ & 427 & 21.1 \\
ABOVE 65 & 269 & 13.3 \\
\hline TOTAL & $\mathbf{2 0 2 6}$ & $\mathbf{1 0 0}$ \\
\hline
\end{tabular}

Source: Author's Field Survey, 2013

In the above tabular presentation (table 1), it shows that for the rural dwellers, the highest number of respondents who utilize development information falls within the age bracket 46-55 (560 respondents or 27.6\%) This is closely followed by age bracket 36-45 (448 respondents or 22.1\%), and 56-65 (427 respondents or $21.1 \%)$. It therefore follows that the majority of rural dwellers who participated in the study were within age brackets 36-65 (1435 respondents or 70.8\%). Those within the age brackets of 16-35 and above 65 constituted the lowest number of respondents (591 or $29.2 \%$ ). It goes therefore to show that majority of those who utilize development information are mainly older adults. Perhaps for the problem of rural- urban drift, a few young adults were involved in the study as shown in table 1

The finding here supports Okafor (1981) who stated that the age of an individual is very important to the utilisation of an innovation and Arowojolu (1998), Akinbode and Clark (1968) who reported that older adults are more likely to participate and utilize innovations because they are more receptive to new technologies as they have already established ideas and practices.

Research question 2: What is the distribution of respondents who utilize development information by marital status?

Table 2: Distribution of Respondents (rural dwellers) by Marital Status

\begin{tabular}{|l|l|l|}
\hline Marital Status & Frequency & Percentage \\
\hline Single & 191 & 9.4 \\
Married & 1084 & 53.5 \\
Separated & 339 & 16.7 \\
Divorced & 46 & 2.3 \\
Widowed & 366 & 18.1 \\
\hline Total & $\mathbf{2 0 2 6}$ & $\mathbf{1 0 0}$ \\
\hline
\end{tabular}

Source: Author's Field Survey, 2013

From table 2, it is evident that 1084 or $53.5 \%$ of the rural dwellers are married, 366 or $18.1 \%$ are widowed, 339 or $16.7 \%$ are either separated from their wives or husbands, 191 or $9.4 \%$ are single and 46 or $2.3 \%$ are divorced. On the whole, more respondents (1084 or 53.5\% rural dwellers) are married, compared to the number of those who are single, separated, divorced or widowed. It therefore goes to show by implication that, the incidence of divorce is alien to the rural people. It was observed that rather than divorce, men are encouraged to marry as many wives as they can cater for. And, where the marriage broke down, separation rather than outright divorce was preferred by both parties.

This finding corroborates Adeogun (2008) who tested the correlation betwext6en selected variables and utilization/participation in cocoa rehabilitation techniques in selected states in Nigeria. He found out that marital status, among other variables was significantly associated with utilisation and participation in the programme. 
Research question 3: What is the distribution of respondents who utilize development information by educational qualification?

Table 3: Distribution of Respondents (Rural dwellers) by Educational Qualification.

\begin{tabular}{|l|l|l|}
\hline Educational Qualification & Frequency & Percentage \\
\hline 1. First School Leaving Certificate (FSLC) & 490 & 24.2 \\
\hline $\begin{array}{l}\text { 2. West African School Certificate (WASC) Senior Secondary School Certificate/ } \\
\text { National Examination Council(NECO). }\end{array}$ & 410 & 20.2 \\
\hline 3. Nigerian Certificate Of Education(NCE) & & \\
\hline 4. Bachelor's Degree (BSC, B.Ed., B.Agric.etc.) & 914 & 45.1 \\
\hline 5. Master's Degree (MA, MSC, M.Ed.etc.) & 134 & 6.6 \\
\hline 6. Doctor of Philosophy (Ph.D.) & 62 & 3.1 \\
\hline \multicolumn{1}{|l|}{ Total } & 16 & 0.8 \\
\hline
\end{tabular}

Source: Author's Field Survey, 2013

As indicated in table 3 above, 914 or $45.1 \%$ of the respondents hold the National Certificate in Education, 490 or $24.2 \%$ are holders of First School Leaving certificate (FSLC), 410 or $20.2 \%$ have WASC, NECO or SSCE, 134 or $6.6 \%$ hold the Bachelor Degree, 62 or 3.1\% have the Masters Degree and 16 or $0.8 \%$ are holders of the Ph.D. The basic qualification needed for participation in this study was the FSLC for all the respondents.

This goes to prove that education has significant association with participation and utilization in proven innovation. Obibuaku and Hursh (1994), Voh (1982) and Nweke (1981) found a positive correlation between levels of education and response to innovation campaigns in their studies.

Research question 4: What is the distribution of respondents who utilize development information by occupational status?

Table 4: Distribution of Respondents (Rural Dwellers) by occupational status.

\begin{tabular}{|l|l|l|}
\hline Occupational Status & Frequency & Percentage \\
\hline Civil Servants (teachers, nurses, policemen, forestry staff) & 326 & 16.1 \\
Private Employees (farmers, fishermen/women, craftsmen) & & \\
Employers of Labour (owners of farmlands, fish ponds, bakeries) & 601 & 29.7 \\
Retirees & & \\
& 661 & 32.6 \\
& 438 & 21.6 \\
\hline Total & $\mathbf{2 0 2 6}$ & $\mathbf{1 0 0}$ \\
\hline
\end{tabular}

Source: Author's Field Survey, 2013

Table 4 above shows that employers of labour accounted for 661 or $32.6 \%$ of the respondents, private employees 601 or $29.7 \%$, retirees 438 or $21.6 \%$ and the civil servants were 326 or $16.1 \%$.

This goes to show that rural and community development efforts are mainly undertaken by private employees (farmers, fishermen/women, craftsmen), the employees of labour (owners of farmlands, fish ponds, bakeries), and the retirees, while the civil servants (Teachers, nurses, policemen, forestry staff) may not have enough time for participation.

From available research, the relationship between participation/utilization in innovation and occupation as a socio-economic variable is found not to be consistent. Sule et al (2007) and Auta et al (1992) have in their studies found occupation not to be a consistent variable in determining participation or utilization. This is so because occupation sometimes affects utilization positively and at other times, it may not.

Research question 5: What is the distribution of respondents who utilize development information by sex?

Table 5: Distribution of Respondents (Rural Dwellers) by sex.

\begin{tabular}{|l|l|l|}
\hline Category of Respondents & Number & \% of Total Respondents \\
\hline Male & 1015 & 50.1 \\
\hline Female & 1011 & 49.9 \\
\hline Total & $\mathbf{2 0 2 6}$ & $\mathbf{1 0 0}$ \\
\hline
\end{tabular}

Source: Author's Field Survey, 2013

In terms of the total respondents (as indicated in table 5 above), the males were 1015 or $51.1 \%$ while the females accounted for 1011 or $49.9 \%$ of the respondents. This implies that more male rural dwellers did not only participate but also showed keen interest in community and rural development as well as utilization of 
development information than their female counterparts. This shows that more men reside in the rural areas than women and that men participate in information utilization/transfer than female.

This finding is in line with Adeogun (2008) who indicated in his study that, the majority of the respondents who participated in and utilized cocoa rehabilitation techniques in Nigeria were males and, Ojebode (2003) who concluded that one hundred and fifty family planning radio messages recorded in sixteen developing countries clearly varied as the number of sex and audience did.

Table 6: ANOVA on the joint contributions of communication source preference on the utilization of development information among rural dwellers.

\begin{tabular}{|l|l|l|l|l|l|}
\hline Source of Variation & Sum of squares & Df & Mean square & F & Sig. \\
\hline Regression & 1201.865 & 5 & 240.373 & 52.917 & .000 \\
Residual & 9175.689 & 2020 & 4.542 & & \\
Total & 10377.554 & 2025 & & & \\
\hline $\mathrm{R}$ & $=.340$ & $=.116$ & & & \\
$\mathrm{R}^{2}$ & $=.114$ & & & \\
Adj $\mathrm{R}^{2}$ & & & & \\
\hline
\end{tabular}

$*$ Significant Result $(\mathrm{F}(5.2020)=52.971 p<0.05)$

The result in table 6 above shows that communication source preference had significant joint effect on the utilization of development information among rural dwellers $(F=52.917 ; \mathrm{p}>0.05)$. This implies that source preference significantly related to information utilization among rural dwellers.

Apart from the joint contribution of the independent variables, a further test was carried out using multiple regression method to determine the relative contributions of these independent predictors on the utilization of development information among rural dwellers.

Table 7: Summary of regression analysis showing Relative contributions of communication source preference to the utilization of development information among rural dwellers.

\begin{tabular}{|l|l|l|l|l|l|}
\hline Factors & $\boldsymbol{\beta}$ & Std. Error & Beta & T & Sig. \\
\hline Constant & 8.698 & .309 & & 28.161 & .000 \\
\hline $\begin{array}{l}\text { Interpersonal sources (e.g. town crier, community } \\
\text { leader, visits/ contracts, extension agents etc.) }\end{array}$ & .424 & .062 & .162 & 6.860 & .000 \\
\hline Radio & .415 & .069 & .156 & 6.045 & .000 \\
\hline Television & .235 & .072 & .152 & 3.279 & .001 \\
\hline Newspaper/Magazines & .164 & .059 & .086 & 2.801 & .005 \\
\hline Libraries/Information centres & .351 & .048 & .065 & 7.273 & .000 \\
\hline
\end{tabular}

The relative effect of the predictors shows that interpersonal sources e.g. town crier, community leader, visits/contracts etc. $\quad(\beta=.162 ; \mathrm{p}<0.05)$, Radio $(\beta=.156 ; \mathrm{p}<0.05)$ Television $(\beta=.152 ; \mathrm{p}<0.05)$, Newspapers/Magazines $(\beta=.086 ; p<0.05)$ and Libraries/information centres $(\beta=.065 ; \mathrm{p}<0.05)$ had significant effect on the development of utilization of development information.

\section{Discussion Of Findings}

Hezog et al (1968) working on the question of source credibility and preference in Brazil, supports the findings that there is a significant relationship between communication source preference and utilization. He found out in his study that, the extension agents and other interpersonal sources were dominant sources of farm information used by the 1,037 respondents. Radio was ranked third in that study. MacLeod's (1971) survey which also sought to find out the level of credibility credited to some mass media sources found out that next to television, $69.2 \%$ of the respondents found radio very reliable and credible.

Adams (1982) noted that the information channels most preferred by farmers are mass media including radio, television and newspapers, contacts with extension agents and with other farmers. Also, corroborating the findings above, Williams (1984) in his study of sources of farm information indicated that agricultural extension agents were the most important source, closely followed by radio, and then contacts between fellow farmers.

Obibuaku et al (1994) in their diffusion studies in Eastern Nigeria indicated that radio or regular access to it was a major means of reaching the farmers. In his own contribution, Okafor (1981), studying sources of farm information found that information could be disseminated to farmers through news releases, radio messages and television programmes.

The above proves that the constant interaction of the respondents with information sources such as the interpersonal channels (e.g. the extension agent, community leaders, visits/contacts/friends/town crier etc.), radio, television, the print and library has influence utilization behaviour (Ganpat \& Seepersad, 1996). It also corroborates Voh (1979) and Obibukaku and Hursh (1994) who indicated in their studies that a variety of information sources are necessary in information dissemination. Furthermore, the results is in line with Emenyeonu (1987) who indicated that both the educated and uneducated respondent relied heavily on the 
extension agents as a dominant source of information, and Ononamadu (1984) who showed that farmers learned of recommended practice from the radio, television and other media sources.

To corroborate the above findings, participants at the Focus Group sessions indicated the followings:

(i) That the source of communication can influence persuasive efficiency and eventual adoption of development information.

(ii) That a source which the people hold in high esteem appears to facilitate persuasion while a source with low esteem can constitute a setback to development. Hear one of the participants (Mr. Roland Omekpere from Emouha, Rivers State on August 9 $\left.{ }^{\text {th }}, 2006\right)$ :

I have so much respect for my chief. If my chief tell(s) me to do something or follow him, I will (gladly) do so. I was born in this community, and I have live(d) here (since). If government people tell me to do anything, I will refuse because "dem too dey lie lie".

(iii) From the above and similar statements, it was deduced that the use of people who fit the preconceived idea of wisdom in a particular culture makes them seen as a credible source of information. It also implies that most rural people still have respect for tradition. Thus, they will readily accept messages from interpersonal sources such as chiefs'/community leaders, town crier, friends, and neighbours than from mass media sources. It also means that, the paternalistic approach where development experts talk down on the people as if they were children can alienate a whole community and ruin the development experiment.

(iv) Many of the participants said they will readily use information from a source if the media opinion is from an expert or in accordance with the majority view. For instance, Ms. AtimOkpoyo from Oron-Eket, AkwaIbom State said, she would help clean her community or vote a particular candidate if the idea came from her chief, pastor or other members of the community. She however, said that, on health-related matters for example, she would listen first to health officials because they "know everything" (are experts).

(v) Finally, most participants said they would prefer one medium to another because of their status, literacy level, affordability and availability of the channel, and the spread of the message carried by the medium. For example, television, magazine and newspapers are not easily affordable or available to the people. So people do not readily seek information from these media.

The finding here corroborates Katz's two-step flow and Rogers' Diffusion of innovation theories. Katz's theory is of the opinion that, media information flows from media sources (physical - individuals, experts, etc. technical - telephone and social - TV, radio, schools etc.) to opinion leaders who discuss and disseminate same among themselves before passing such through interpersonal channels to the local people. Rogers Diffusion Theory has proved that the dissemination of information is not a simple two-step process. But that both interpersonal and mass channel has their crucial and special roles to play at important stages of innovation delivery. The performance of these roles will therefore depend on whether or not such channels are credible, prestigious, popular, have wide reach and are affordable to the people as sources.

\section{Conclusion}

There seems to be some fundamental misconception surrounding the role of communication media in a developing economy such as we have in Nigeria. There is a need to view communication in all its ramifications by clearly defining and making distinction between communication as a general concept, and development communication as understood and practiced by practitioners, and also distinguish between traditional and modern communication.

On the basis of this, the study therefore recommends not only a marriage of the traditional communication with mass media to provide an array of information sources for rural people as a way of helping them participate meaningfully in development experiment but also that, attention should be paid to a range of communication channels that accounted for qualitative information usage in development processes. These channels must be kept informal, democratic, horizontal and made viable sources of information for development.

\section{Recommendations}

Based on the findings of the study, the following recommendations were made:

1. Like county paths, communication channels need to be kept open, frequented and sometimes repaired if they are to continue to be recognized as viable sources of information for development.

2. Communication channels should be made informal, democratic and horizontal to elicit the participation of the rural people in the development of information.

3. There should be a marriage of traditional and modern communication so as to provide an array of information sources for development. 


\section{References}

[1]. Adams, E. M. (1982). Agricultural Extension in Developing Countries. Intermediate Tropical Agricultural Series. Longman Group Ltd.

[2]. Adeogun, S. O. (2008). Utilisation of Cocoa Rehabilitation Techniques among Cocoa Farmers in Selected States of Nigeria. Ph.D. Thesis of the Department of Adult Education, University of Ibadan.

[3]. Akinbode, A. A., \& Clarke R. C. (1968). Factors associated with utilisation three Farm Practices in the Western State of Nigeria Research bulletin, I, University of Ife. P. 2.

[4]. Angba, O. A. \& Itari, P. E. (2012). Socio-Economic Factors Influencing Farmers Participation in CD Organisations in Obubra L. G. A. of Cross River State, Nigeria. Canadian Social Science, 8(1), Pp. 54-59.

[5]. Arowojolu, O. (1998). Utilisation of Cassava - Maize Intercrop Recommendation Practices in Irele Local Government Area of Ondo State. B.Sc. Thesis Department of Agricultural Extension Services, University of Ibadan, Ibadan 72p

[6]. Auta, S. J., Ariyo, J. A. \& Akpoko, J. G. (1992). Socio-spatial variations in the Utilisation of Agricultural Innovations in Selected Villages in Funtua and Jema Local Government Areas. The Nigerian Journal of Agric. Extension, 17, (1\&2).

[7]. Emenyeonu, N. B. (1987). Communication and Utilisation of Agricultural Innovations: Qualification and Notes Towards a Conceptual Model, Africa Media Review, 1,(2).

[8]. Ganpat, W. \& Seepersad, C. (1996). An Analysis of Linkages in a Rice-based Knowledge system in Trinidad. Proceedings of the $12^{\text {th }}$ annual conference of the Association for International agric and extension education (AIAEE) held at Arlington, Virginia, Pp. 131-136.

[9]. Herzog, W. A., Stanfield, J. D., Whiting, G. C. \& Svenning, L. (1968). Patterns of Diffusion in Rural Brazil. A USAID-funded Research Project. Michigan State University.

[10]. Ifidon, S. E \& Ahiazu, B. (2005). Information and Conflict Prevention in the Niger-Delta Region of Nigeria. African Journal of Library, Archives and Information Science, 15(2), Pp. 125-132.

[11]. Itari, P. E, Anthony, G. B \& Ukeme, I. (2015). Personal factors as Determinants of utilization of Development information in Rural Communities of South-South Geo-political zone, Nigeria. Journal of Education and Practice, 6(3), Pp. 97-105.

[12]. Itari, P. E, Beshel, C. A. \& Ukeme, I. (2015). Indigenous Communication Media and Utilisation of Development Information in Rural Communities of south-south, Nigeria. International Journal of English and Literature (IJEL), 5(7), Pp. 85-96.

[13]. MacLeod, M. (1971). Notes on the Mass Media in Sub-Sahara Africa in Rawson-Jones and Salkeld G. (eds) Communicating Family Planning England: IPPF Pp. 58-63.

[14]. Mchombu, K. J. (1992). Information Needs for Rural Development: The Case Study of Malawi, Africana Journal of Library: Achieves \& Information Science, 2(1), Pp. 17-32.

[15]. Nweke, F. I. (1981). Determinants of Agricultural Progressiveness in the Small-Holder Cropping System of the Southern Nigeria. Agricultural Administration 8, Pp. 163-176.

[16]. Obibuaku, L. O. \& Hursh, G. D. (1994). Farm Practice Utilisation in the Eastern States of Nigeria. Agricultural Administration, 1, p. 117.

[17]. Ojebode, A. (2003). Radio as a Development Communication Medium: Types, Formats, Roles and Limitations in Soola, E.O (Ed.) 2003. Communicating for Development Purposes Ibadan: Kraft Books Limited.

[18]. Okafor, F. C. (1981). Measuring the Spatial Dimension of Rural Development: Constraints and Problems in Falola, J.A et al (eds.) Nigerian Environments: Status and Trendskano: Bayaro university, Pp 80-84.

[19]. Ononamadu, E. O. (1984). The Impact of World Bank Rice Project on Rice Production in Akwa and Nsukka Agricultural Zones. M.Sc. Thesis, UNN. P. 9

[20]. Quebral, N. (2001). Development Communication Borderless World. A Paper Presented at The National Conference-Workshop On the Undergraduate Development Communication Curriculum. Continuing Education Centre, UP Los Banos; Department of Science Communication. University of Philippines Los Banos pp 15-28.

[21]. Rogers, E. M. (1995). Diffusion of Innovation. New York: Free Press

[22]. Soola, E. O. (1999). Traditional and Modern Communication Media Use and Strategies for Effective Environmental Awareness. Journal of Communication and Language Arts, 1(1), Pp. 32-44.

[23]. Sule, A. M., Olowosegun, T., Sanni, A. O., \& Bawala, R. L, (2007). Socio-Economic Variables Affecting the Utilisation of Solar Tent Technology is Kainji lake basin. The Nigerian Theory of Rural Extension and Development, 2. Pp 18-27.

[24]. Uzuegbunam, C. O. (1981). An Appraisal of the Impact of the NAPFF on Farmers in Anambra State. M.Sc. Thesis UNN.

[25]. Voh, J. P. (1984). Farm Technology Utilisation, Farmers in Gusau Agricultural Development Project Villages, Journal Issues in Development 1(1), Pp. 26-37.

[26]. Voh, J. P. (1982). A study of Factors Associated with the Utilisation of Recommended farm Practices in a Nigerian village. Agricultural Administration, 9, p.5.

[27]. Williams, S. K. T., \& Williams, G.E. (1969). Sources of Information Improved Farming Practices in Some Selected Areas of Nigeria. Bulletin of Rural Economics and Sociology, 4, No.1. 